\title{
Optical study on the fuel spray characteristics of the four-consecutive-injections strategy used in high-pressure isobaric combustion
}

\author{
Qinglong Tang1, Ramgopal Sampath ${ }^{1}$, Priybrat Sharma ${ }^{1}$, Gustav Nyrenstedt ${ }^{1}$, Abdullah AIRamadan ${ }^{1}$, \\ Moez Ben Houidi' ${ }^{1}$, Jihad Badra ${ }^{2}$, Bengt Johansson' ${ }^{1}$, Gaetano Magnotti ${ }^{1}$ \\ 1 King Abdullah University of Science and Technology, Clean Combustion Research Center, Thuwal, 23900, Saudi Arabia \\ 2 Fuel Technology Division, R\&DC, Saudi Aramco, Dhahran 31311, Saudi Arabia
}

\begin{abstract}
High-pressure isobaric combustion used in the double compression expansion engine (DCEE) concept was proposed to obtain higher engine brake thermal efficiency than the conventional diesel engine. Experiments on the metal engines showed that four consecutive injections delivered by a single injector can achieve isobaric combustion. Improved understanding of the detailed fuel-air mixing with multiple consecutive injections is needed to optimize the isobaric combustion and reduce engine emissions. In this study, we explored the fuel spray characteristics of the four-consecutiveinjections strategy using high-speed imaging with background illumination and fuel-tracer planar laser-induced fluorescence (PLIF) imaging in a heavy-duty optical engine under non-reactive conditions. Toluene of $2 \%$ by volume was added to the $n$-heptane and served as the tracer. The fourth harmonic of a $10 \mathrm{~Hz} \mathrm{Nd:YAG} \mathrm{laser}$ was applied for the excitation of toluene. The PLIF image distortion caused by the side window curvature and the optical piston was mitigated using a correction lens and corrected with a grid mapping technique. The effects of hydraulic delay and injection dwell on the in-cylinder liquid-phase fuel penetration and vapor-phase fuel distribution were evaluated under different combinations of the four direct injections. The high-speed imaging of the liquid-phase spray shows that a short injection dwell reduces the hydraulic delay of the injector, resulting in an increase in both the peak liquid-phase penetration length and the injection duration. The fuel-tracer PLIF imaging clarifies the spatial fuel distribution of the four consecutive injections involved with the interaction between the vapor-phase spray and the piston bowl wall and the squish region. The intensity distribution in the PLIF images confirms that a longer injector hydraulic delay leads to a shorter peak vapor-phase spray penetration length and a reduced flow rate.
\end{abstract}

\section{Introduction}

High internal combustion (IC) engine efficiency is a major factor in reducing the greenhouse $\mathrm{CO}_{2}$ emission from the transportation sector. Many strategies for engine thermal efficiency improvement have been investigated over the years. From an ideal IC engine thermodynamic cycle perspective, the Otto cycle with constant volume combustion is preferable at the constant compression ratio [1]. To approach the Otto cycle, a fast combustion rate is needed. The homogenous charge compression ignition (HCCI) concept [2], or HCCI-like concepts like partially premixed combustion (PPC) [3] and reactivity controlled compression ignition (RCCI) [4], can yield higher engine efficiencies compared to the traditional diesel or sparkignition engine due to the faster combustion rate. In addition, PPC and RCCI feature the low-temperature combustion, hence reducing the heat transfer loss and contributing to a higher gross indicated engine efficiency of more than $50 \%[5,6]$.

The ideal thermodynamic efficiency of the Otto cycle increases with the compression ratio. However, the actual engine brake efficiency decreases at high compression ratios due to the increasing heat transfer loss and lower mechanical efficiency (high friction loss) due to increased combustion pressures and temperatures $[7,8]$. In order to overcome these limitations, Lam et al. $[9,10]$ proposed a double compression expansion engine (DCEE) concept that is composed of a two-stage compression and expansion cycle by using two cylinders, one low-pressure (LP) cylinder and one high-pressure (HP) cylinder. They showed that in a DCEE, it is possible to simultaneously reach both high indicated and mechanical efficiency by splitting the engine into two different cycles, high-pressure and low-pressure cycles respectively. The main advantage of this concept is that the separate HP cylinder has a small in-cylinder wall surface that reduces the heat transfer loss, while the separate LP cylinder reduces the overall friction loss by using less rigid engine configuration compared to the HP cylinder.

The high engine brake efficiency of a DCEE requires a peak cylinder pressure of 300 bar, close to the maximum allowed pressure. It cannot afford further pressure rise during the combustion close to the top dead center, and thus the DCEE cycle requires isobaric combustion. Studies on heavy-duty engines showed that it was possible to achieve isobaric combustion using only one common-rail diesel injector with a four-consecutive-injections strategy [11, 12]. Four short fuel injections closely spaced in time can achieve isobaric combustion. However, this strategy requires a fast and robust response of the common rail injection system. Aljohani et al. [13] studied the injector flow rates of single and split injections under atmospheric pressure and temperature using a piezoelectric pressure sensor. They highlighted the effects of the hydraulic delay and injection dwell on the injector flow rates. However, their potential effects on fuel spray characteristics and the overall in-cylinder fuel distribution remain unexplored.

With this background, it is of interest to study the combustion phenomena when utilizing a single-injector strategy for isobaric combustion. In the present study, we investigated the fuel spray 
characteristics of the four-consecutive-injections strategy used in the previous high-pressure isobaric combustion work [11], on a heavyduty optical engine under non-reactive conditions. Two optical diagnostic techniques were applied. Firstly, a high-speed camera coupled with background illumination recorded the liquid-phase fuel injection process. Secondly, the fuel-tracer planar laser-induced fluorescence (PLIF) was employed to visualize the in-cylinder fuel distribution. Although the experiment was carried out under nonreactive conditions, this study can gain insight into the potential effect of hydraulic delay and injection dwell on fuel spray characteristics and the overall in-cylinder fuel distribution for the four-consecutive-injections strategy. This work also provides valuable validation data for the relevant spray modeling for isobaric combustion.

\section{Experimental setups}

The experiment was carried out on a four-stroke, heavy-duty optical engine that was modified from a Volvo D13C500 diesel engine. Only one of the cylinders was enabled and redesigned for optical study. The optical engine was equipped with three optical windows on the side, as shown in Figure 1, and a Bowditch extended piston with an optical piston crown that has $\omega$ piston bowl shape, as shown in Figure 2 . The main optical engine specifications are summarized in Table 1. The diameter of the optical piston and piston bowl are $130 \mathrm{~mm}$ and $92 \mathrm{~mm}$, respectively. A six-hole diesel injector with a hole diameter of $248 \mu \mathrm{m}$ and a spray included angle of $147^{\circ}$ was used.

Table 1. Optical engine specifications

\begin{tabular}{|l|l|}
\hline Displaced volume & $2.130 \mathrm{~L}$ \\
\hline Stroke & $158 \mathrm{~mm}$ \\
\hline Bore & $131 \mathrm{~mm}$ \\
\hline Connecting Rod & $255 \mathrm{~mm}$ \\
\hline Compression ratio & 12.5 \\
\hline Fuel injection system & Delphi F2 Common Rail \\
\hline
\end{tabular}

Table 2. Engine operating conditions

\begin{tabular}{|l|l|}
\hline Engine speed & $1200 \mathrm{rpm}$ \\
\hline Intake gas & $\mathrm{N}_{2}$ \\
\hline Intake pressure & $1 \mathrm{bar}$ \\
\hline Intake temperature & $25^{\circ} \mathrm{C}$ \\
\hline Coolant temperature & $60^{\circ} \mathrm{C}$ \\
\hline Oil temperature & $60{ }^{\circ} \mathrm{C}$ \\
\hline Fuel & $98 \%$ v-heptane $+2 \%_{\mathrm{v}}$ toluene \\
\hline Injection pressure & 1500 bar \\
\hline
\end{tabular}

Table 3. Fuel injection strategy

\begin{tabular}{|c|r|c|}
\hline No. of injections & Injection timing & Injection duration \\
\hline $1^{\text {st }}$ injection & $-4^{\circ} \mathrm{CA}$ ATDC & $200 \mu \mathrm{s}\left(1.4^{\circ} \mathrm{CA}\right)$ \\
\hline $2^{\text {nd }}$ injection & $1^{\circ} \mathrm{CA}$ ATDC & $200 \mu \mathrm{s}\left(1.4^{\circ} \mathrm{CA}\right)$ \\
\hline $3^{\text {rd }}$ injection & $4^{\circ} \mathrm{CA}$ ATDC & $220 \mu \mathrm{s}\left(1.6^{\circ} \mathrm{CA}\right)$ \\
\hline $4^{\text {th }}$ injection & $8.3^{\circ} \mathrm{CA}$ ATDC & $300 \mu \mathrm{s}\left(2.2^{\circ} \mathrm{CA}\right)$ \\
\hline
\end{tabular}

The engine was motored at 1200 revolutions per minute (rpm) during the experiment. All the spray measurements were carried out under non-reactive conditions by supplying $\mathrm{N}_{2}$ through the intake. The fuel used in the study is n-heptane and toluene of $2 \%$ by volume was added into the $n$-heptane to serve as the tracer for PLIF imaging. The fuel injection pressure was kept at 1500 bar. The average cylinder pressure and temperature at TDC are about 32 bar and $810 \mathrm{~K}$, respectively. Other engine operating conditions are listed in Table 2.

Injection timings and durations for the four-consecutive-injections strategy employed in [11] to achieve isobaric combustion are listed in Table 3. The injection duration of the first two injections at $-4^{\circ}$ and $1^{\circ}$ crank angle after the top dead center (CA ATDC) are the same. The injection duration of the third and fourth injection at $4^{\circ}$ and $8.3^{\circ}$ CA ATDC is gradually increased to maintain the cylinder pressure under later direct injection timings in the mentioned study. The corresponding fuel injection duration in crank angle for these four injections are $1.4^{\circ} \mathrm{CA}, 1.4^{\circ} \mathrm{CA}, 1.6^{\circ} \mathrm{CA}$ and $2.2^{\circ} \mathrm{CA}$, respectively.

Two test matrixes were carried out. Firstly, the number of injections was increased sequentially, resulting in four cases of $1^{\text {st }}$ injection only, $1^{\text {st }}+2^{\text {nd }}$ injections, $1^{\text {st }}+2^{\text {nd }}+3^{\text {rd }}$ injections and $1^{\text {st }}+2^{\text {nd }}+3^{\text {rd }}+4^{\text {th }}$ injections. By comparing these four cases, we can learn the effect of the later injections on the overall in-cylinder fuel distribution. Secondly, the cases with separate single injections $\left(1^{\text {st }}, 2^{\text {nd }}, 3^{\text {rd }}\right.$ and $\left.4^{\text {th }}\right)$ were compared to the case with all four injections $\left(1^{\text {st }}+2^{\text {nd }}+\right.$ $3^{\text {rd }}+4^{\text {th }}$ ) to study the effect of injection dwell on the spray characteristics and in-cylinder fuel distribution. All the test points are listed in Table 3.

Table 3. Test matrixes

\begin{tabular}{|c|c|}
\hline No. of test & Fuel injection combinations \\
\hline 1 & $1^{\text {st }}$ injection \\
\hline 2 & $1^{\text {st }}+2^{\text {nd }}$ injections \\
\hline 3 & $1^{\text {st }}+2^{\text {nd }}+3^{\text {rd }}$ injections \\
\hline 4 & $1^{\text {st }}+2^{\text {nd }}+3^{\text {rd }}+4^{\text {th }}$ injections \\
\hline 5 & $2^{\text {nd }}$ injection \\
\hline 6 & $3^{\text {rd }}$ injection \\
\hline 7 & $4^{\text {th }}$ injection \\
\hline
\end{tabular}

\section{Fuel-tracer PLIF imaging}

The fourth harmonic (266 nm, $60 \mathrm{~mJ} /$ pulse) of a $10 \mathrm{~Hz} \mathrm{Nd:YAG}$ laser (Q-smart850) was chosen for the toluene tracer excitation. The laser beam was formed into a vertical laser sheet less than $0.5 \mathrm{~mm}$ thick and $20 \mathrm{~mm}$ high by the laser sheet optics composed of three cylindrical lenses $\left(f_{l}=-20 \mathrm{~mm}, f_{2}=+100 \mathrm{~mm}\right.$ and $\left.f_{3}=+1000 \mathrm{~mm}\right)$. The laser was introduced through the lower window shown in Figure 1 to cut the centerline of the fuel jet next to the lower window.

An ICCD camera (Princeton, PI-MAX3), equipped with a $100 \mathrm{~mm}$, $\mathrm{f} / 2.8 \mathrm{UV}$-lens (CERCO 2178, Sodern), was placed on the left side of the quartz liner and was tilted so that the whole targeted fuel spray region could be visualized. One correction convex cylindrical lens was designed and installed on the left window to correct the image distortion caused by the left window. A tilt/shift lens mound adapter (Scheimpflug adapter) rotated the camera lens to a certain angle relative to the camera to correct the focus shift produced by the tilting of the ICCD camera. A band-pass filter (FF01-285/14, Semrock) with a transmission range of $278-292 \mathrm{~nm}$ was coupled to the lens to collect the toluene PLIF signal. The gate width and gain level of the ICCD

Page 2 of 7 
camera were $100 \mathrm{~ns}$ and 85 . Due to the low frequency of the laser, only one PLIF image could be acquired from one engine cycle. Fifty images at the same crank angle were processed to get the averaged PLIF image.

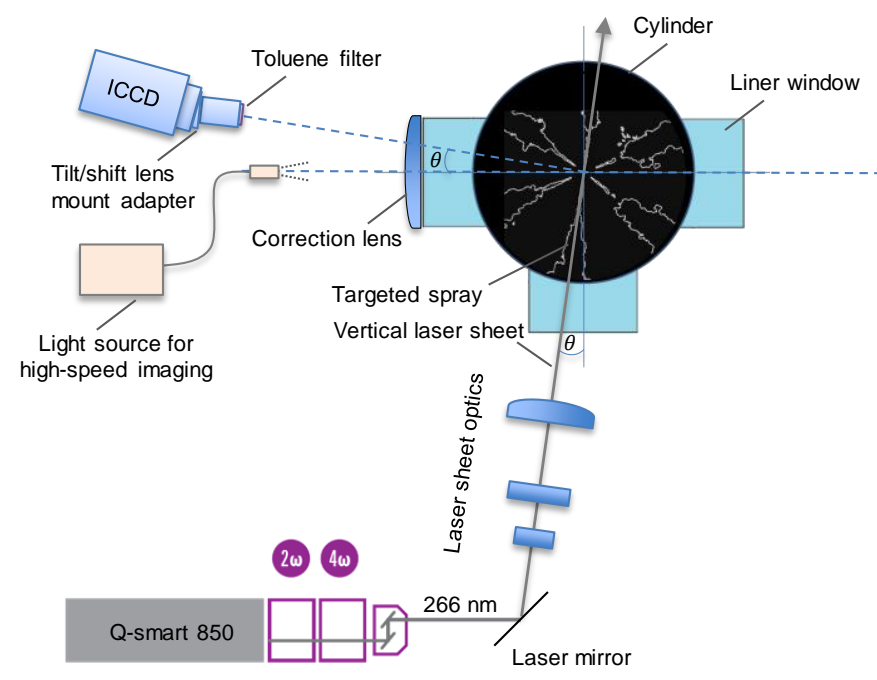

Figure 1. Schematic of the PLIF system. The light source is only enabled in the high-speed imaging of the vapor-phase spray test.

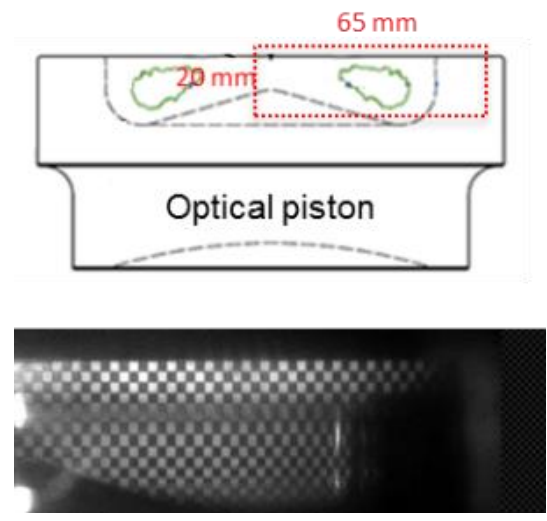

Figure 2. Field of view for the PLIF imaging marked with a red dashed rectangle on the optical piston and distorted grid paper image.

The field of view of the ICCD camera is shown in Figure 2. The convex cylindrical correction lens was chosen to minimize distortions introduced by the window's curvature, but it is insufficient to account for distortions introduced by the quartz piston. The target grid inside the cylinder shows that the distortion caused by the window is minor and only exists in the horizontal direction. This distortion can be corrected easily, however, the distortion caused by the quartz piston is much larger, which poses a great challenge to the image quality. In particular, Figure 2 shows that the high curvature from the piston bowl top and bottom introduces local distortions that are too large for correction during data processing.

One raw PLIF image averaged from 50 images at $14^{\circ}$ ATDC is shown in the upper panel of Figure 3. The PLIF images correction process is as follows: Firstly, the background images were subtracted from the averaged PLIF image. Secondly, the PLIF image with direct injection was corrected by the normalized image acquired at the same Page 3 of 7 crank angle with the port injection that forms a uniform mixture. This step removes the potential effects of laser sheet non-uniformity and the laser energy attenuation caused by the piston bowl wall. The image is then separated into two regions, one above, and one below the piston bowl top. The distortion in the upper image is caused by the optical liner while the distortion in the lower image by both the optical liner and the piston bowl. Thus, these two parts are corrected separately based on the grid-mapping using MATLAB image processing toolbox. A similar correction procedure can be found in our previous work [14] and the works of Wang et al.[15] and Miles et al. [16]. Finally, the two parts of the distortions-corrected images were combined and a mask with the piston top and bowl boundary was applied to the image to show the spatial relationship between the fuel jet and the piston bowl. A small region (1.5 mm thick) along the piston top surface is masked because the local distortion is too large to be removed in post-processing.

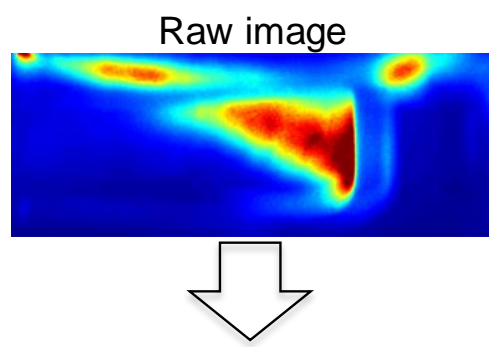

\section{BK subtraction and normalization using port injection}
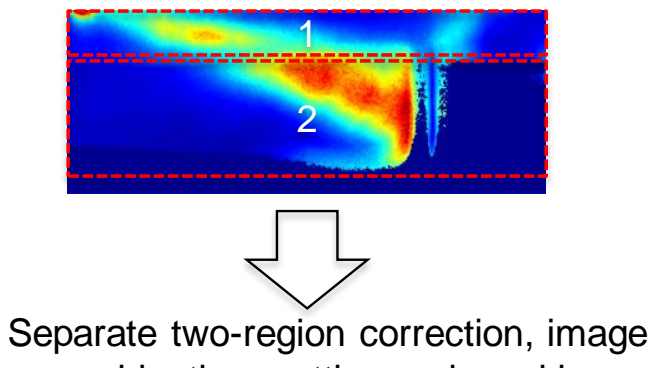
combination, cutting and masking

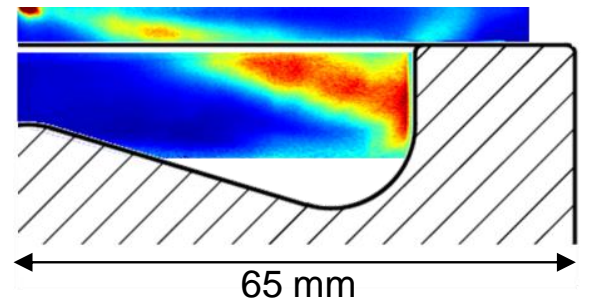

Figure 3. PLIF Image distortion correction process.

\section{High-speed imaging of the liquid-phase spray}

In order to show the time-resolved liquid-phase fuel injection timing of the four consecutive fuel injections, a CMOS high-speed camera (Photron SA4) was used to record the Mie scattering signal of the liquid-phase fuel duration injection from the bottom of the optical piston. A light source provides the background illumination for the spray from the left window shown in Figure 1. 
Figure 4 shows the field of view for the high-speed camera and one typical liquid-phase fuel spray image at $11.4^{\circ} \mathrm{CA}$ ATDC for the case with only the $4^{\text {th }}$ injection. The frame rate and exposure time of the high-speed camera were $36 \mathrm{kHz}$ and $10 \mu \mathrm{s}$, respectively, resulting in a time resolution of $0.2^{\circ} \mathrm{CA}$. Only the targeted fuel spray on the right-hand side was chosen for post-processing. The time-resolved liquid-phase penetration length was quantified to indicate the actual fuel injection process. This provides useful information about the hydraulic delay and injection duration.

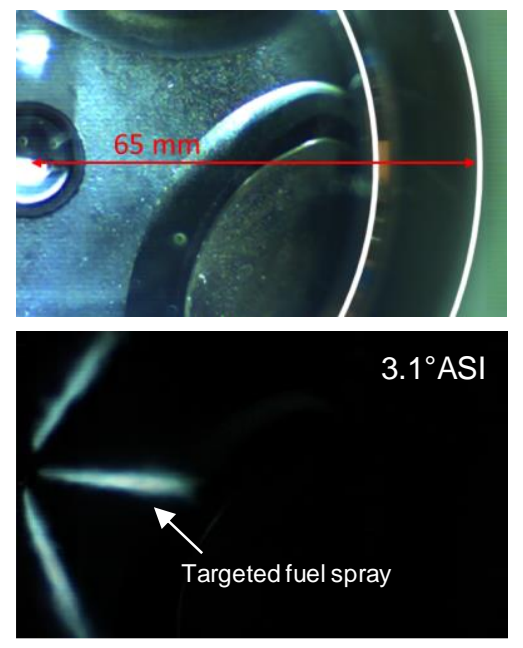

Figure 4. Field of view for the high-speed imaging and one example of the liquid-phase spray at $3.1^{\circ} \mathrm{CA}$ after the start of injection (ASI) for the case with only the $4^{\text {th }}$ injection at $8.3^{\circ} \mathrm{CA}$ ATDC

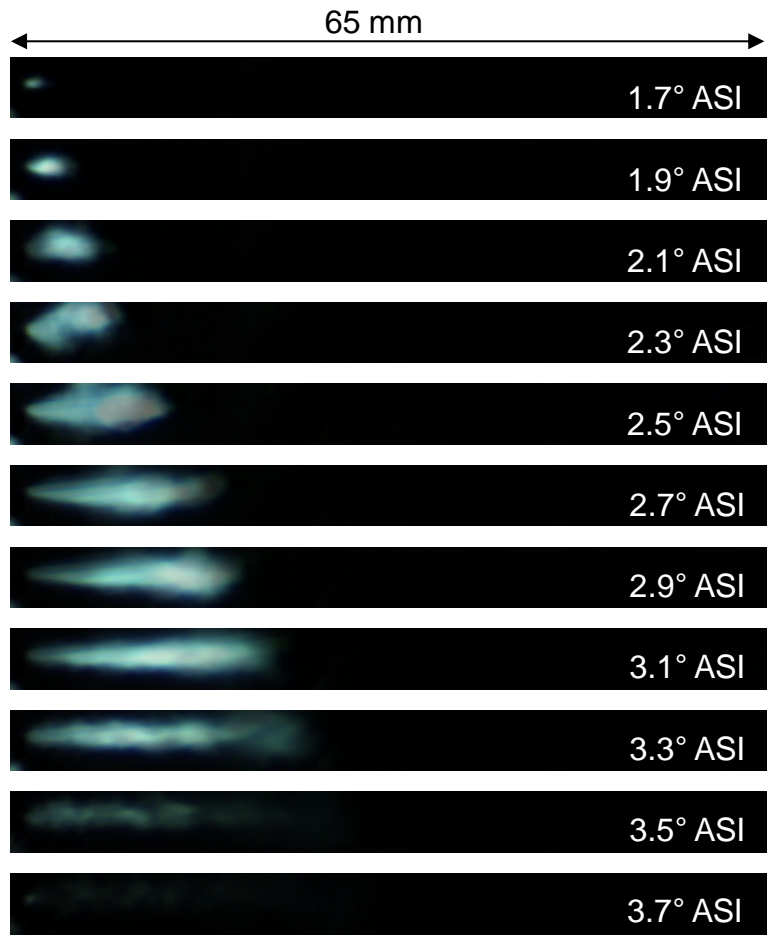

Figure 5. High-speed imaging of the liquid-phase targeted fuel spray after the start of injection (ASI) for the case with only the $4^{\text {th }}$ injection at $8.3^{\circ} \mathrm{CA}$ ATDC. Each image is averaged for 10 cycles at the same crank angle. A background light source was used to illuminate the spray.

Page 4 of 7

\section{Results and discussion}

\section{Liquid-phase spray imaging and penetration length}

Figure 5 shows one example of the targeted liquid-phase fuel spray development from $1.7^{\circ}$ after the start of injection (ASI, $10^{\circ} \mathrm{CA}$ ATDC) to $3.7^{\circ}$ ASI $\left(12^{\circ} \mathrm{CA}\right.$ ATDC) for the case only with the $4^{\text {th }}$ injection after image rotation and cropping. Each image is averaged from ten cycles at the same crank angle. By image binarization and edge detection using $10 \%$ of the peak scattered light intensity, we can obtain the actual liquid-phase penetration length.

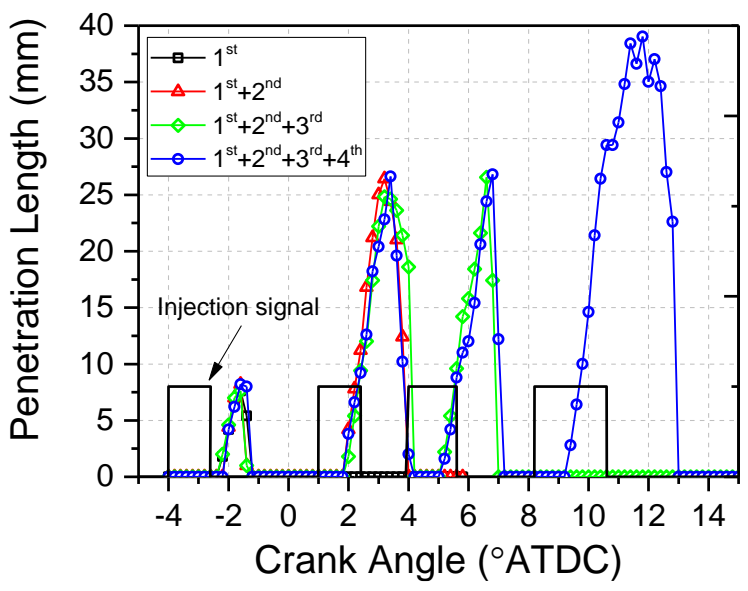

Figure 6. Averaged liquid-phase spray penetration length for cases with a sequentially increased number of fuel injections. The four injection signals set in the control software are shown with black rectangles.

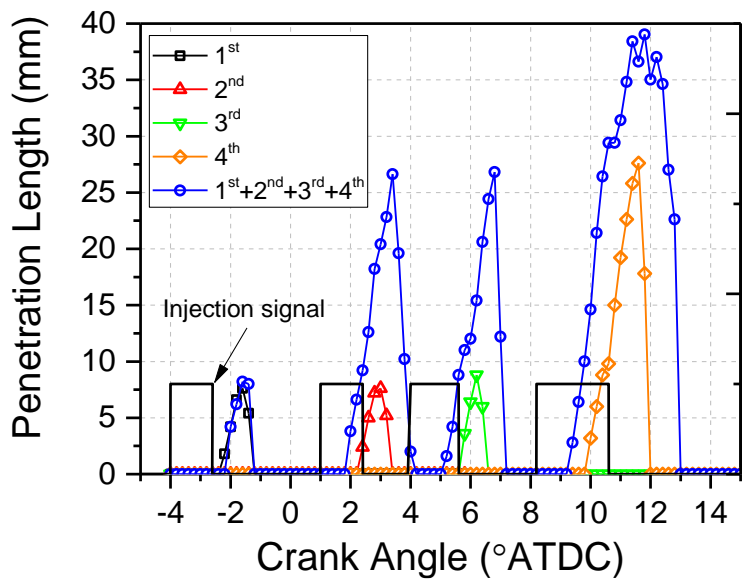

Figure 7. Averaged liquid-phase spray penetration length for cases with all four injections and separated single injection. The four injection signals set in the control software are shown with black rectangles.

Figure 6 presents the penetration length for cases with a sequentially increased number of fuel injections. The actual fuel injection orders set in the common-rail system are marked as black rectangles. We can see that the hydraulic delay of the first injection is about $2{ }^{\circ} \mathrm{CA}$, which is longer than that of the other three injections that are about $1{ }^{\circ} \mathrm{CA}$. Recall that the first two fuel injections have the same injection 
duration. Compared to the second fuel injection, the difference in hydraulic delay decreases the liquid-phase penetration length and injection duration and thus the fuel mass delivered by the first fuel injection. The fourth injection shows the longest peak liquid-phase penetration length about $40 \mathrm{~mm}$, which is shorter than the radius of the piston bowl $(46 \mathrm{~mm})$, indicating that the wall wetting issue is not a problem under 1500 bar injection pressure for this optical engine.

Figure 7 shows the spray penetration length for cases with all four injections and separated single injections. The cases with separated single injections remove the effect of injection dwell (the interval between two adjacent injections), indicating the original and designed fuel injection characteristics. By comparing the cases with separate single injections and all four injections combined, we can see that the injection dwell has a great impact on the fuel delivered by the later injection. If the interval is small enough (less than $5^{\circ} \mathrm{CA}$ in this study), the actual fuel mass delivered by the later injection gets higher because the reduced hydraulic delay increases both the injection duration and the peak liquid-phase penetration length.

When the injection duration is around $200 \mu$ s for the first three injections, the peak liquid-phase penetration length increase from 8 $\mathrm{mm}$ to $27 \mathrm{~mm}$ due to the effect of the reduced hydraulic delay. In comparison, for the $4^{\text {th }}$ injection with an injection duration of $300 \mu \mathrm{s}$, the peak liquid-phase penetration length only increases from $28 \mathrm{~mm}$ to $39 \mathrm{~mm}$. This means that the reduced injector hydraulic delay has a greater effect on the actual peak liquid-phase penetration length for the cases with short injection duration.

The effect of injection dwell time on the injector needle response makes it difficult to calibrate the injector flow rate when using multiple injections that are close to each other, like the four consecutive injections in the present study. The next section will discuss how the hydraulic delay and injection dwell affect the incylinder fuel distribution.

\section{In-cylinder fuel distribution shown by the PLIF imaging}

Figure 8 shows the averaged PLIF images of the cases with the increasing number of fuel injections: $1^{\text {st }}+2^{\text {nd }}, 1^{\text {st }}+2^{\text {nd }}+3^{\text {rd }}$ and $1^{\text {st }}+2^{\text {nd }}+3^{\text {rd }}+4^{\text {th }}$. Except for the $1^{\text {st }}+2^{\text {nd }}+3^{\text {rd }}+4^{\text {th }}$ case at $12^{\circ} \mathrm{CA}$, all the PLIF measurement timings are after the end of fuel injections, as shown in Figure 6. We notice that the PLIF image acquired during the injection process, namely the PLIF of the liquid-phase fuel, shows stronger distortion even after the correction. This can be attributed to the additional image distortions caused by the liquid-phase spray during injection that could not be corrected by using the grid mapping technique. The PLIF image scale is varied based on the peak signal intensity by using the different gain factors, as shown in the figure with $\times 10$ being a gain of 10 .

The PLIF images of the $1^{\text {st }}+2^{\text {nd }}$ case from $4^{\circ}$ to $10^{\circ} \mathrm{CA}$ indicates that the fuel-air mixture formed by the first two injections is mainly confined to the piston bowl and does not reach the piston bowl wall by $10^{\circ} \mathrm{CA}$. By comparing the $1^{\text {st }}+2^{\text {nd }}$ case and the $1^{\text {st }}+2^{\text {nd }}+3^{\text {rd }}$ case at $8^{\circ}$ and $10^{\circ} \mathrm{CA}$, we can observe that the mixture formed by the third injection reaches the piston bowl wall at $10^{\circ} \mathrm{CA}$, forming a local fuel-rich region near the wall. Recall that the liquid-phase penetration length is shorter than the piston bowl radius and thus the near-wall region is the vapor-phase fuel-air mixture. By the time of $12^{\circ}$ and $14^{\circ}$ $\mathrm{CA}$, the near-wall fuel-rich region becomes leaner and some fuel starts to enter into the piston squish volume. When comparing the $1^{\text {st }}+2^{\text {nd }}+3^{\text {rd }}$ case and the $1^{\text {st }}+2^{\text {nd }}+3^{\text {rd }}+4^{\text {th }}$ case at $12^{\circ}$ and $14^{\circ} \mathrm{CA}$, we can notice that more vapor-phase fuel of the $4^{\text {th }}$ injection impinges on the side piston bowl wall forming a larger local fuel-rich zone and more fuel gets into the piston squish by $14^{\circ} \mathrm{CA}$. By the timings of $16^{\circ}$ and $18^{\circ} \mathrm{CA}$, the field of view in the piston squish has almost been filled with fuel-air charge, indicating that the fuel in the piston squish mainly comes from the fourth injection.

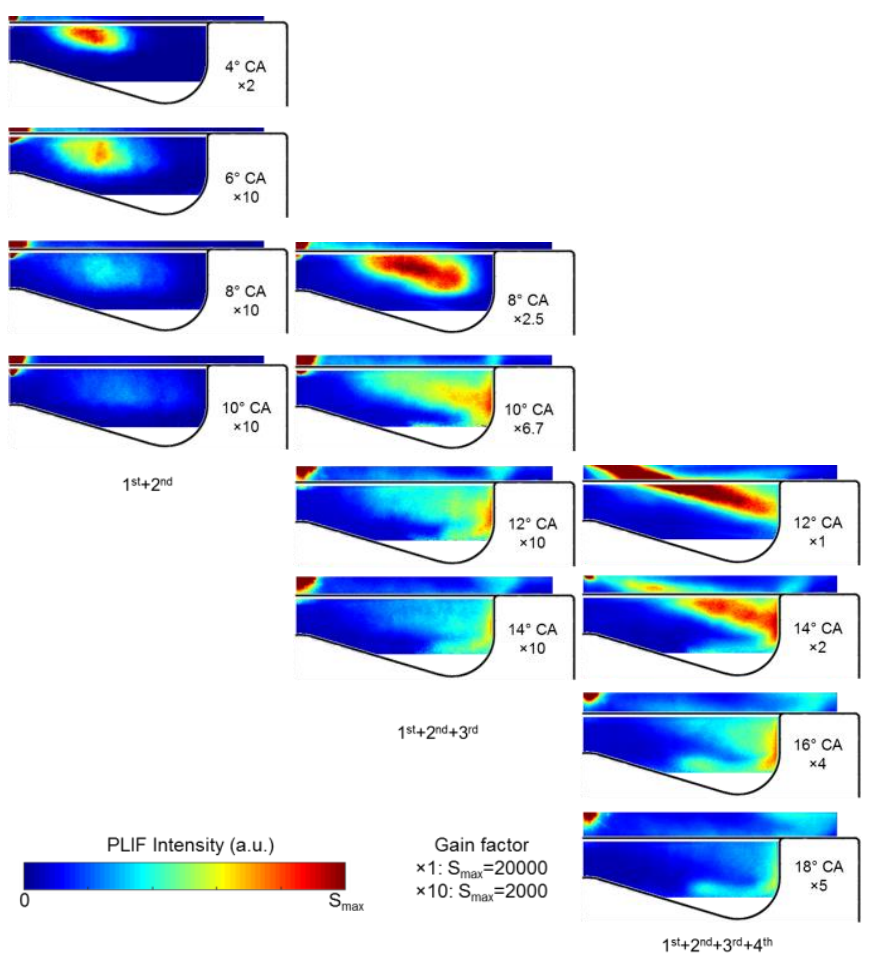

Figure 8. Averaged PLIF images of the fuel spray for cases with a sequentially increased number of fuel injections. The peak PLIF intensity of the images, $\mathrm{S}_{\max }$, is shown with different gain factors.

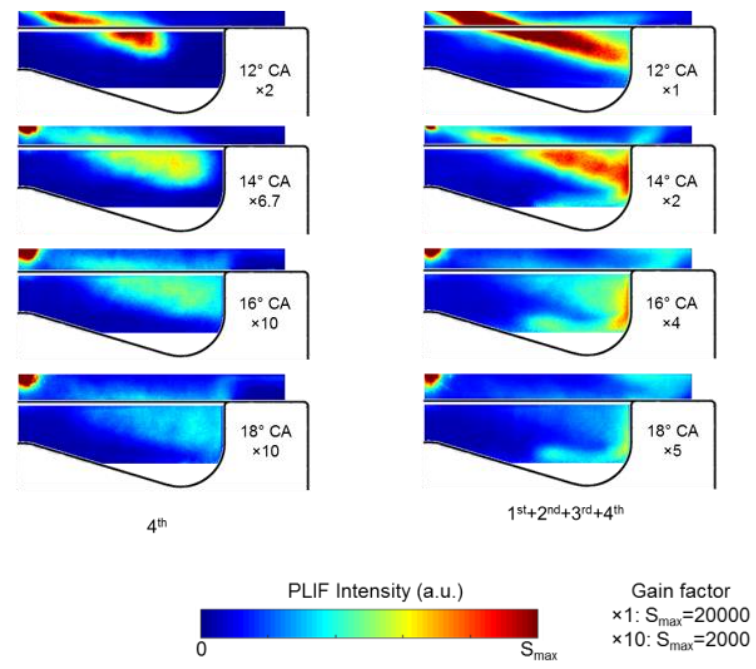

Figure 9. Averaged PLIF images of the fuel spray for cases with the fourth injection only and all four injections. The peak PLIF intensity of the images, $\mathrm{S}_{\max }$, is shown with different gain factors.

Page 5 of 7 
Figure 9 compares the in-cylinder fuel distribution of the case with the $4^{\text {th }}$ injection only and the case with all four injections. It shows that the case with the $4^{\text {th }}$ injection only has much shorter spray penetration length at $12^{\circ} \mathrm{CA}$ compared to the case with all four injections. The vapor-phase spray with much lower PLIF intensity does not even reach the piston bowl wall by $14^{\circ} \mathrm{CA}$, indicating much lower delivered fuel mass or reduced mixing. By the timings of $16^{\circ}$ and $18^{\circ} \mathrm{CA}$, the mixture formed by the case with only the $4^{\text {th }}$ injection is mainly confined to the piston bowl and no evident fuel mixture enters into the squish volume by $18^{\circ} \mathrm{CA}$.

For all the cases in Figure 8 and Figure 9, the PLIF images show distinct injector dribbling after the end of fuel injection. The PLIF images provide insight into the fuel distribution inside the piston bowl and the piston squish and further proves the main findings regarding the effects of hydraulic delay and injection dwell as indicated in Figure 6 and 7.

\section{Summary/Conclusions}

High-speed imaging with background illumination and fuel-tracer PLIF were applied on a heavy-duty optical engine to study the fuel spray characteristics of the four-consecutive-injections strategy used in high-pressure isobaric combustion $[11,12]$. The PLIF image distortion caused by the side window and optical piston was corrected using a correction optic and the grid mapping technique. The effects of hydraulic delay and injection dwell on the in-cylinder liquid-phase fuel penetration and vapor-phase fuel distribution were evaluated with different combinations of the four direct injections. The main conclusions are listed as follows:

(1) The four-consecutive-injections strategy, which was employed in the isobaric combustion concept using only one direct-injection injector, poses a great challenge in the actual injector flow rate calibration. This is because the very short injection dwell (less than $5^{\circ} \mathrm{CA}$ ) reduces the hydraulic delay of the later injections and thus increases the actual flow rate under the same injection duration setting.

(2) The high-speed imaging of the liquid-phase spray shows that a shorter injection dwell reduces the hydraulic delay of the injector with a consequent increase of both the liquid-phase penetration length and the injection duration.

(3) There is no liquid-phase spray-wall impingement in the fourconsecutive-injections strategy using 1500 bar injection pressure. The injector hydraulic delay has a greater effect on the actual peak liquidphase penetration length for the cases with short injection duration.

(4) The fuel-tracer PLIF imaging indicates that the first two injections in the four-consecutive-injections strategy are confined in the piston bowl, showing no evident interaction between the vapor-phase spray and piston bowl wall. In comparison, the vapor-phase spray of the third injection touches the piston bowl wall. A more intense interaction between the vapor-phase spray and the piston bowl wall is witnessed for the fourth injection and most of the vapor phase fuel trapped in the piston squish comes from the fourth injection.

(5) The effect of the longer injector hydraulic delay on the in-cylinder fuel distribution was verified by the PLIF imaging, showing a shorter vapor-phase spray penetration length and low PLIF intensity that indicates a reduced flow rate.

Page 6 of 7

\section{References}

1. Heywood J. Internal Combustion Engine Fundamentals: McGraw Hill, Inc, 1988.

2. Dec J. Advanced compression-ignition engines - understanding the in-cylinder processes. P Combust Inst. 2009; 32(2):2727-42.

3. Kalghatgi GT, Risberg P, Angstrom H. Advantages of fuels with high resistance to auto-ignition in late-injection, lowtemperature, compression ignition combustion. SAE 2006-043385. 2006.

4. Kokjohn SL, Hanson RM, Splitter DA, Reitz RD. Fuel reactivity controlled compression ignition (RCCI): a pathway to controlled high-efficiency clean combustion. Int J Engine Res. 2011; 12(3):209-26.

5. Splitter D, Hanson R, Kokjohn S, Reitz RD. Reactivity controlled compression ignition (RCCI) heavy-duty engine operation at mid- and high-loads with conventional and alternative Fuels. SAE 2011-01-0363. 2011.

6. Manente V, Johansson B, Cannella W. Gasoline partially premixed combustion, the future of internal combustion engines? Int J Engine Res. 2011, 12(3):194-208.

7. Okamoto T, Uchida N. New concept for overcoming the tradeoff between thermal efficiency, each loss and exhaust emissions in a heavy duty diesel engine. SAE International Journal of Engines. 2016, 9(2):859-67.

8. Liu HF, Ma JS, Tong LH, Ma GX, Zheng ZQ, Yao MF. Investigation on the Potential of High Efficiency for Internal Combustion Engines. Energies. 2018;11(3).

9. Lam N, Tuner M, Tunestal P, Andersson A, Lundgren S, Johansson B. Double Compression Expansion Engine Concepts: A Path to High Efficiency. SAE International Journal of Engines. 2015, 8(4).

10. Lam N, Andersson A, Tunestal P. Double Compression Expansion Engine Concepts: Efficiency Analysis over a Load Range. SAE Technical Paper, 2018-01-0886, 2018.

11. Babayev R, Ben Houidi M, Andersson A, Johansson B. Isobaric combustion: a potential path to high efficiency, in combination with the double compression expansion engine (DCEE) concept. SAE Technical Paper, 2019-01-0085, 2019.

12. Babayev R, Houidi MB, Shankar VB, Aljohani B, Johansson B. Injection strategies for isobaric combustion. SAE Technical Paper, 2019-01-2267, 2019.

13. Aljohani BSE, Ben Houidi M, Babayev R, Aljohani K, Johansson B. In situ injection rate measurement to study single and split injections in a heavy-duty diesel engine. SAE Technical Paper, 2019-24-0136, 2019.

14. Tang Q, An Y, Raman V, Shi H, Sim J, Chang J, et al. Experimental study on the effects of spray-wall interaction on partially premixed combustion and engine emissions. Energ Fuel. 2019, 33(6):5673-81.

15. Wang Z, Lonn S, Matamis A, Andersson O, Tuner M, Alden M, et al. Transition from HCCI to PPC: investigation of fuel distribution by planar laser induced fluorescence (PLIF). SAE International Journal of Engines. 2017, 10(4).

16. Miles PC, Collin R, Leif H, Hultqvist A, Andersson O. Combined measurements of flow structure, partially oxidized fuel, and soot in a high-speed, direct-injection diesel engine. $\mathrm{P}$ Combust Inst. 2007, 31:2963-70. 


\section{Contact Information}

Qinglong Tang

Postdoctoral Fellow

Clean Combustion Research Center

King Abdullah University of Science and Technology

Building 5, Level 4, Room 4216, WS12

Thuwal 23955-6900, Saudi Arabia

Telephone: +966 (0) 54470 1526, +86 15900359894

Email: qinglong.tang@kaust.edu.sa

\section{Acknowledgments}

The paper is based upon work supported by Saudi Aramco Research and Development Center FUELCOM3 program under Master Research Agreement Number 6600024505/01. FUELCOM (Fuel Combustion for Advanced Engines) is a collaborative research undertaking between Saudi Aramco and King Abdullah University of Science and Technology (KAUST) intended to address the fundamental aspects of hydrocarbon fuel combustion in engines and develop fuel/engine design tools suitable for advanced combustion modes. 